\title{
Impact of the COVID-19 pandemic on Easter
}

\author{
Charles S. Pavia · Maria M. Plummer
}

Received: 5 November 2020 / Accepted: 17 March 2021 / Published online: 8 April 2021

(C) Springer-Verlag GmbH Austria, part of Springer Nature 2021

\section{Dear Editors,}

This commentary is meant to be a more contemporary follow-up discussion to the interesting recently published article by Wormser [1], who discussed some of the major challenges imposed on the Christmas holidays by the current coronavirus disease 2019 (COVID19) pandemic. As the Easter and Passover holiday seasons approach, it has become apparent that many of the activities traditionally associated with these annual festivities will be compromised worldwide due to the pandemic even though anti-severe acute respiratory syndrome coronavirus 2 (SARS-CoV-2) vaccines have been recently developed and many people are receiving them at a relatively rapid rate. These include large-scale shopping for food and gifts, large gatherings of families and friends to share meals and gifts, attendance at religious services, and the likely above-average travel on buses, planes and railway systems. In addition, there is the anticipated arrival of the so-called Easter Bunny, which has been considered to be a folkloric figure associated with Easter, depicted as a unique rabbit bringing holiday treats. Originating among a certain German religious group, a few centuries ago the Easter Bunny originally played the role of a judge, evaluating whether children were good or disobedient in behavior at the start of the season of Eastertide [2]. Over time, the Easter Bunny

\section{S. Pavia, Ph.D. $(\bowtie)$}

Department of Biomedical Sciences, New York Institute of Technology, College of Osteopathic Medicine, Old Westbury, NY 11568, USA

cpavia@nyit.edu

\section{M. Plummer, M.D.}

Department of Clinical Specialties, New York Institute of Technology, College of Osteopathic Medicine, Old Westbury, NY 11568, USA has taken on more of a secular image and is sometimes depicted wearing clothes. Based on legend, it carries colored eggs in its basket, candy, and sometimes also toys to the homes of children and, as such, shows similarities to the activities of Santa Claus during Christmas. They both bring gifts to children on the night before their respective holidays. Some people believe that the custom was first mentioned in the physician Georg Franck von Franckenau's "De ovis paschalibus" (translated as: "About Easter Eggs”) in 1682 [3], referring to a German tradition of an Easter hare bringing eggs for the children. Perhaps of paramount importance, especially to families with young children, will be the health status of the Easter Bunny, in a manner somewhat similar to what was well-stated by Wormser for the challenges that were going to be faced by Santa Claus during his annual worldwide gift-giving journey [1]. The major issue here is whether the Easter Bunny will be able to distribute, as is done traditionally for Easter, colored eggs and candy gifts to the many homes that it will visit globally without contracting COVID-19 and then possibly serving as a super spreader, as it moves from house to house.

In this respect, the Easter Bunny may seem to be especially vulnerable to infection with SARS-CoV-2 based, in part, on the historical use of the rabbit for studies in various infectious disease-related disorders, as a susceptible animal model, although it can produce high levels of antibodies (rabbits are well known for having an excellent humoral immune response to a diverse group of antigens of both infectious and noninfectious origin and have been used as a source of high-titer immune sera for over a century), which could afford protection against an infectious agent. Along these lines, a very recent study [4] showed that they could be experimentally infected with SARSCoV-2. The good news is that the infected rabbits 
showed no signs of serious disease manifestations. There was, however, significant nasal carriage, which could render the rabbits as asymptomatic carriers, but this appeared to occur only temporarily. Furthermore, according to the website for the People's Dispensary for Sick Animals [5], a veterinary charity in the United Kingdom, rabbits can catch COVID-19 from infected humans but do not develop symptoms and are not contagious to other rabbits or any other species. It is not clear whether "any other species" refers to the human species but it would seem that humans are more a risk to rabbits than rabbits are to humans, which is another reason people should still wear masks and follow proper handwashing and social distancing during this upcoming Easter season.

In addition, there are other equally valid reasons why the Easter Bunny may not have to cancel its gift-giving spree. This unique and highly specialized member of the lagomorph family has managed to survive past outbreaks of almost similar severity to COVID-19, which affected both humans and various animal species. Most notable of these would include the 3rd plague pandemic that began in 1870 [6] and the 1918 flu pandemic. Both of these outbreaks wreaked much havoc resulting in millions of deaths worldwide. Also, as far as we know, except for its advancing age, the Easter Bunny has never suffered from any other possible comorbidities, such as having to receive chemotherapy for treating any type of neoplastic disorder that would seriously weaken its immune system and, thus, make it more susceptible to a wide range of opportunistic pathogens, along with SARS-CoV-2.

Lastly, as an added precaution, the Easter Bunny could be in line for one of the anti-COVID-19 vaccines that have become available for widespread use, a few weeks before beginning its gift-giving travels. In fact, there have been unconfirmed reports that the Easter Bunny had volunteered to be a test subject in one of the phase 2 animal vaccine trials that showed $>95 \%$ protection, and thus would have acquired protective immunity if it was part of the vaccine-recipient group and not the placebo group.

So, what should the Easter Bunny do for the 2021 Easter season in the midst of the current pandemic?
Irrespective of whether it has received a vaccine or has natural immunity bestowed upon it via a prior unrecognized infection with SARS-CoV-2 that leads to viral neutralization, like many of us impacted by the current pandemic, it should, while traveling throughout the world on its annual journey, follow the safety recommendations of the World Health Organization and other internationally recognized experts [7]. These would include taking the appropriate protective measures of wearing facial coverings, practicing social distancing, and washing its paws with soap and water, or hand sanitizer, after each household visit. Thus, we should feel confident that this specialized purveyor of holiday treats will not be at risk for either acquiring or transmitting COVID-19.

Author Contribution Both authors contributed to the conceptualization and writing of the manuscript.

Conflict of interest C.S. Pavia and M.M. Plummer declare that they have no competing interests.

\section{References}

1. Wormser GP. Impact of COVID-19 on Christmas. Wien Klin Wochenschr. 2020; https://doi.org/10.1007/s00508-02001765-z.

2. Cross G. Wondrous innocence and modern American children's culture. Oxford: University Press; 2004.

3. von Franckenau, GF.1682. Disputatione ordinaria disquirens de ovis paschalibus / von Oster-Eyern. 1682. Satyrae Medicae.XVIII. Heidelberg, Germany. p. 6.

4. Mykytyn AZ, Lamers MM, Okba NMA, Breugem TI, Schipper D, van den Doel PB, et al. Susceptibility of rabbits to SARS-CoV-2. Microbes Infect. 2021;10(1):1-7. https:// doi. org/10.1080/22221751.2020.1868951.

5. People's dispensary for sick animals.. https://www. pdsa.org.uk/taking-care-of-your-pet/pet-health-hub/ conditions/coronavirus-and-covid-19-in-pets. Accessed 5 Mar 2021.

6. Gainer R. Yamal and anthrax. Can VetJ. 2016;57(9):985-7.

7. Horton R. The Covid-19 catastrophe. Cambridge: Polity Press; 2020.

Publisher's Note Springer Nature remains neutral with regard to jurisdictional claims in published maps and institutional affiliations. 